I find it difficult to judge whether Schrödinger was truly great - as a the second division. In his early work his mathematical skill was alloyed with a baser metal, and the contaminant did not allow him to judge the physical plausibility of everything he did. He was perfectly in his element, mathematical manipulation, when dealing with his wave equation, and the sunburst of solutions that accompanied its first publication. Yet that moment in his life had no precedent and was not to be repeated, despite some notable contributions to relativity. He was certainly farsighted in his pushing for physics to be extended to form the foundations of biology, but his inclinations to the tenets of Eastern religions (as far as an orthodox scientist can judge) acted as a scientist; as a man he was no conventional saint. I suspect that he was a great man of

cataract to dim his vision. He also wrote poetry (particularly to pull in a harpoon that had been let slip to achieve an amorous conquest); again, as far as I can judge from the numerous examples in the text, he was not a poet.

Physics is certainly the better for Schrödinger's existence, and that is the essence of true immortality. Dublin was also undoubtedly intellectually enriched by his lengthy sojourn there and his early moulding of its famous Institute, and that is a valuable contribution to civilization. Some friends, I suspect, have been left not a little poorer; but in the great accounting, perhaps friends don't count, especially if you think you are God Almighty. After all, what is life?

P.W. Atkins is in the Physical Chemistry Laboratory, University of Oxford, and is a Fellow of Lincoln College, Oxford OX13DR, UK.

\section{Light work}

\section{O. S. Heavens}

The Fabry-Perot Interferometer: History, Theory, Practice and Applications. By J. M. Vaughan. Adam Hilger:1989. Pp. 583. $£ 60, \$ 130$.

UNTIL the arrival of the laser, optics tended to be dismissed as one of the bits of physics that was essentially completely dealt with. James Clerk Maxwell had after all given a comprehensive and fundamental description of light - a mere slice of the broader spread of the electromagnetic spectrum - which accounted elegantly for all the known phenomena such as propagation, interference, diffraction and scattering. Although the need to recognize the quantum character of light (and the wave character of matter) somewhat disturbed the serenity, there seemed no need to revise the essentials of Maxwell's ideas, nor to expect any dramatic developments.

Nobel prizes flowed steadily in the direction of particle physicists - until 1964. In that year the award of the prize to Townes, Prokhorov and Basov signalled the return of optics to the frontier region. Following the notions outlined by Einstein in 1917, which were exploited in the microwave region of the spectrum in 1954 (maser), the laser appeared in 1960 and rapidly transformed most areas of optics. Within a few years, many of the quantities associated with 'ordinary' light sources had changed by many orders of magnitude, especially intensity, brightness and monochromaticity. By now there are few disciplines in the sciences and engineering that have not been profoundly affected.

Both the operation of the laser and many of its remarkable applications are based on the Fabry-Perot interferometer, a deceptively simple device consisting of two flat, partly silvered glass plates rigidly bed by Perot and Fabry in 1899 , the device immediately made it possible to determine the wavelength of spectral lines to an unprecedented accuracy - better than one part in a million. The historical background provided in this book leaves one fascinated and full of admiration for the thoroughness and ingenuity of the experimenters at the turn of the century.

The step to the laser was in a sense very simple. Take a pair of Fabry-Perot plates, pull them apart, and place a discharge tube (say a neon sign) in between them. (This was in fact tried by Tolansky in 1956 - not to try to make a laser but to "see what happened". Nothing did.) When things are properly adjusted an intense light beam, less than a millimetre in diameter, streams out of the system. The apparent simplicity belies the great usefulness of a light beam which has very regular oscillations (coherence), is of high intensity and has an extremely well-

Dr Vaughan gives many examples of the dramatic contributions which the laser, in conjunction with the Fabry-Perot interferometer, has made to the fields of atomic spectroscopy, astronomy, astrophysics, light-scattering, metrology, infrared detection and many others. In fact, the content of the book is much broader than the title suggests, in that the 70 or so pages of appendix bring the reader thoroughly up to date with the whole range of the many associated techniques needed to exploit this remarkable device to the full. The book will be enjoyed at many levels - for its historical interest, as an overall perspective of some 25 years of exciting developments and as a valuable source of information on the state of the art.

O. S Heavens is in the Department of Physics, University of York, York Y01 5DD, UK. held parallel to one another. First descridefined wavelength (colour).

\section{Opiates for the people}

\section{Peter Newmark}

Brainstorming: The Science and Politics of Opiate Research. By Solomon $\mathrm{H}$. Snyder. Harvard University Press: 1989. Pp. 208. \$22.50. To be published in Britain next month, $£ 17.95$.

President Bush's administration has just declared war on drugs, and wants to spend an extra two billion dollars next year in controlling the problem. Vast sums will go into law enforcement, prison space, education, workplace inspections and media campaigns. Half a billion dollars in all will be set aside to fight the battle against the trafficking barons in South America and in providing protection for the legal officers who stick to their unenviable jobs. The same amount will be spent on increasing and improving drug treatment, which is particularly poor for cocaine users.

How much extra is to be spent on biomedical research, which might lead to completely new approaches to the prevention and treatment of drug addiction? Nothing, as far as can be told. Could it be that the amount is so little as not to warrant a mention? Or that the swashbuckling image is so important to those who formulate strategy that the scientists simply did not stand a chance? Or is it that the President was given a pre-publication copy of Solomon Snyder's thoughtful new book, but gave it too narrow a reading?

It was Richard Nixon's war on drugs, launched in 1971 to counter an epidemic of heroin addiction, that also launched Snyder into opiate research. At that time, he "hardly knew heroin from horseradish" but did know Jerome Jaffe, the man that Nixon put in charge of an office created to coordinate drug-abuse programmes. Jaffe and Snyder were both trained as psychiatrists in the 1960s and had become interested in the biological approach to mental illness, so Snyder's suggestion that some money should be spent on drug research centres received a sympathetic hearing. But such was the opposition to spending on research rather than treatment, that it was many months before Snyder found himself applying for a share of the two million dollars to be spread among six research centres.

Snyder was convinced that his first goal should be to establish the site of action of opiates and to identify the cell-surface receptor through which he was sure they acted. But suspecting that such a project would be thought too bold by his peers, he adopted the well-known ploy of applying for funds to carry out research on 